Deep Coseismic Slip in the Cascadia Megathrust can be Consistent with Coastal Subsidence

Diego Melgar, Valerie J. Sahakian \& Amanda M. Thomas

Department of Earth Sciences, University of Oregon

"Corresponding author: dmelgarm@uoregon.edu

This is a non-peer reviewed pre-print submitted to EarthArXiv. This paper has been submitted to Geophysical Research Letters for review.

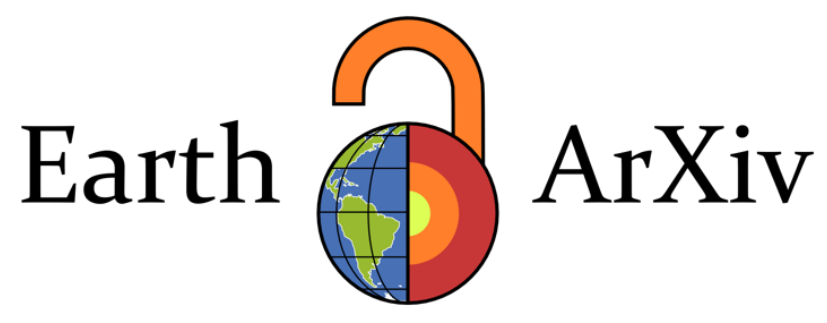




\title{
Deep Coseismic Slip in the Cascadia Megathrust can be Consistent with Coastal Subsidence
}

\author{
Diego Melgar, Valerie J. Sahakian \& Amanda M. Thomas \\ Department of Earth Sciences, University of Oregon
}

\begin{abstract}
At subduction zones, the down-dip limit of slip represents how deep an earthquake can rupture. For hazards it is important - it controls the intensity of shaking and the pattern of coseismic uplift and subsidence. In the Cascadia Subduction Zone, because no large magnitude events have been observed in instrumental times, the limit is inferred from geological estimates of coastal subsidence during previous earthquakes; it is typically assumed to coincide approximately with the coastline. This is at odds with geodetic coupling models, it leaves residual slip deficits unaccommodated on a large swath of the megathrust. Here we will show that ruptures can penetrate deeper into the megathrust and still produce coastal subsidence provided slip decreases with depth. We will discuss the impacts of this on expected shaking intensities.
\end{abstract}

\section{Plain language summary}

We know that large earthquakes at the Cascadia subduction zone, in the Pacific Northwest of the U.S., are possible. In order to understand how strong shaking will be when this occurs and how the coast will subside, we need to know how deep into the Earth the fault can move. The deeper this limit is, the stronger the shaking will probably be. In Cascadia, because we have not observed a large event in the last few centuries, it is difficult to determine this limit. The common wisdom, from analysis of geological samples, is that this limit is fairly shallow. However, if this were true, it would lead to some contradictions with other behaviors observed in Cascadia. Here we show that it is possible for the limit to be deeper so long as the next earthquake has certain properties. This deeper limit resolves the contradictions but it also implies that shaking in the next big earthquake can be significantly stronger than previously anticipated.

\section{Key Points}

- Deep coseismic slip is possible in Cascadia if slip tapers with depth

- Slip can extend into the slow-slip zone

- Deeper slip can produce overall higher intensity ground motions in some regions

\section{Motivation}

The Cascadia Subduction Zone (Figure 1, CSZ) is a $1200 \mathrm{~km}$ plate boundary that extends from the Mendocino Triple Junction in Northern California to the tectonically complex region surrounding the Explorer Plate offshore of Northern Vancouver Island (Braunmiller and Nabelek, 2002; Savard et al. 2020). It accommodates roughly $4 \mathrm{~cm}$ of annual convergence between the Juan de Fuca and North American plates (DeMets et al., 2010). It is well established that the CSZ hosts magnitude 9+ earthquakes and is the dominant source of seismic hazard in the region (Petersen et al. 2020).

The most recent great earthquake occurred in 1700 , this is supported by a variety of geologic observations summarized in Walton \& Staisch, et al. (2021). Across the margin there are instances of sand over mud contacts interpreted to represent sudden coseismic subsidence and deposition soon after caused by a tsunami. Microfossil analyses at coastal marshes show subsidence (Figure 2). Similarly, there is evidence of deep-sea turbidite deposits in cores, these are inferred to be deposited simultaneously at locations across the plate boundary and are thought to be seismically-induced. Historical documents in Japan reveal that a tsunami occurred in Honshu at sites as far as $\sim 800 \mathrm{~km}$ apart without an accompanying earthquake. From these documents Satake et al. (2003) and Atwater et al. (2005) deduced the amplitudes of the tsunami 
there and hydrodynamic modeling found that an earthquake in the M8.7-M9.2 range rupturing most of the CSZ could simultaneously explain the North-American and Japanese observations.

Despite this knowledge, quantifying seismic hazards has been challenging because recurrence intervals are long, and no large events have occurred in the instrumental record. Geodetic locking models (Schmalzle et al., 2014, Li et al., 2018) can provide estimates of fault moment rates but do not resolve the offshore region clearly. Paleoseismic inferences of magnitudes and recurrences of events (Goldfinger et al., 2012, 2017; Nelson et al., 2021) can be used as well. This information can be combined with suitable ground motion models (GMMs) (e.g. Abrahamson et al., 2014), which estimate the severity of ground motions for an earthquake as a function of magnitude, source dimensions, distance, and local geology to make inferences about likely shaking and its probability of occurring. Similarly, simulations based on state-of-theart techniques are used as added sources of information (Frankel et al., 2018; Wirth et al, 2018; Huang and Ramos, 2019; Ramos et al. 2021).
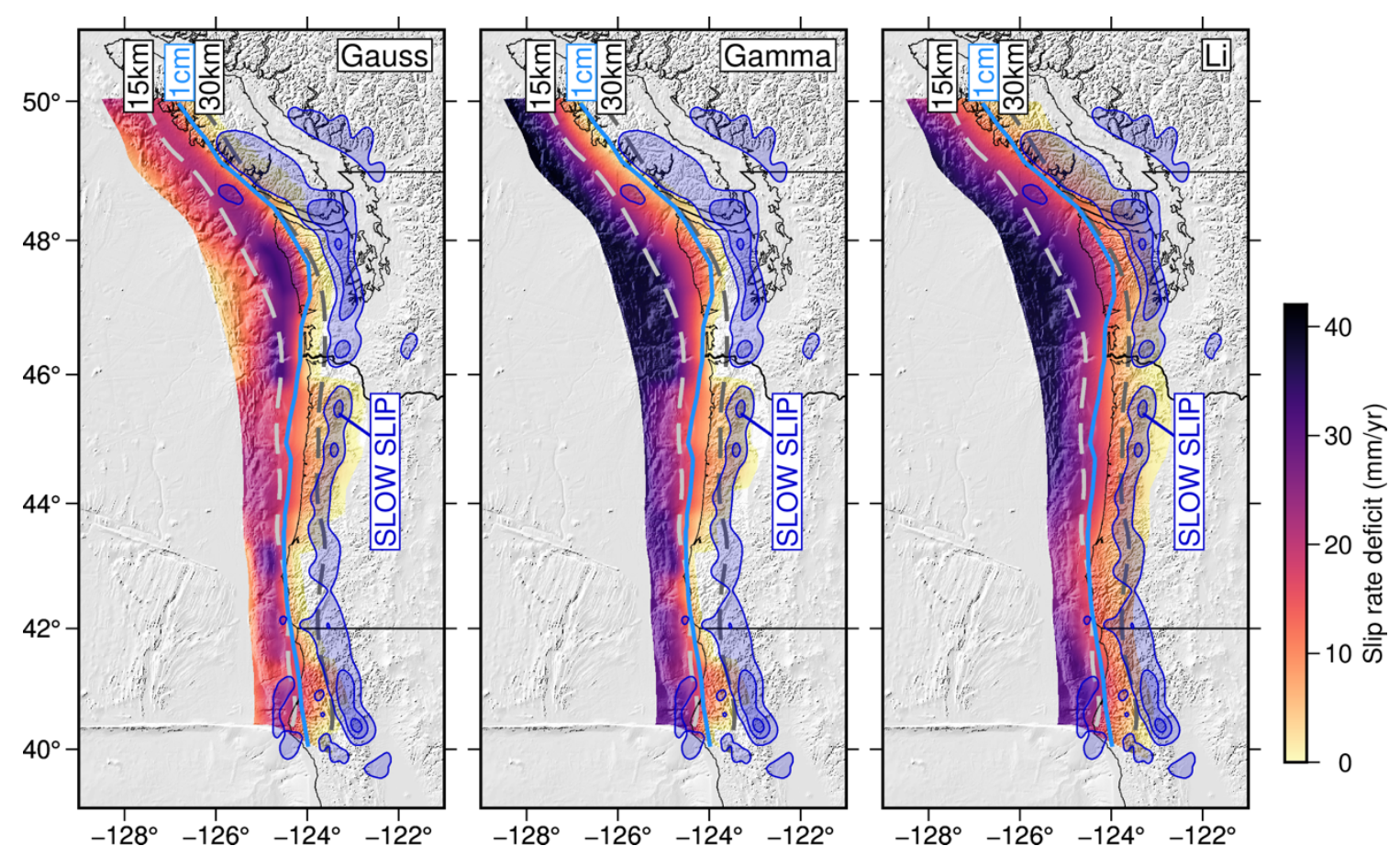

Figure 1. The Cascadia subduction zone and geodetic coupling models. The Gamma and Gauss models are from Schmalzle et al. (2014), the Li model is from Li et al. (2018). "1cm" is the down-dip edge with the highest weight in the National Seismic Hazard Map Petersen et al. (2020). The slow slip region is the aggregated slip zone from Bartlow (2019). The $15 \mathrm{~km}$ and $30 \mathrm{~km}$ slab depth contours are from Hayes et al. (2018)

When estimating earthquake-related hazards, a down-dip limit to how deep rupture can progress into the megathrust must be defined (e.g. Petersen et al., 2020). This boundary determines how far inland the earthquake can rupture and how close it comes to population centers. In simple dislocation models of lowangle thrust faults with homogenous slip, the "hinge line" demarcates the transition between coseismic uplift and subsidence and occurs at roughly the same distance inland as this down-dip edge of slip (Okada 1985, Witter et al., 2014). . Given that margin wide coastal subsidence is inferred to have occurred during the 1700 event (e.g. Kemp et al., 2018), it is commonly assumed that the hinge line, and thus the down-dip limit of slip for great CSZ earthquakes, must be roughly at the coast or somewhere offshore (e.g Hyndman \& Wang, 1995). Recognizing that there is uncertainty in this, the current national seismic hazard map (NSHM) uses three different down-dip limits as part of a logic tree approach to calculating total hazard. Two of the limits are offshore and account for $70 \%$ of the contribution to the total hazard. The third limit 
extends to the top of the slow slip (SSE) zone (Petersen et al., 2020). In support of the view that to be consistent with paleoseismic subsidence an offshore limit is preferrable, Wirth \& Frankel (2019), used the " $1 \mathrm{~cm}$ " down-dip limit from the NSHM to model future CSZ events (Figure 1). From their modeling and overall in the NSHM calculations (Petersen et al., 2020), it is argued that ruptures that extend deeper than this would produce coastal uplift, contravening the geologic inferences, and are thus considered geophysically unlikely.

This leaves a potential contradiction. Models of coupling at the CSZ megathrust (Figure 1) derived from long-term geodetic measurements (Schmalzle et al. 2014, Li et al., 2018) routinely image slip deficit rates as high as $\sim 10-20 \mathrm{~mm} / \mathrm{yr}$ in some regions below the $1 \mathrm{~cm}$ down-dip limit. Additionally, this limit leaves a significant gap between the downdip extent of slip and the up-dip limit of the area known to produce slowslip events (Figure 1, Bartlow, 2019). So, if this region between offshore down-dip limits used in the NSHM and the slow slip region has non-zero geodetic coupling, but is inferred to not participate in coseismic rupture, how does it release accumulated slip deficits?

Here we compute thousands of stochastic kinematic rupture scenarios of large magnitude earthquakes on the CSZ. We generate five different families of simulations, each taking into account different down-dip limits and patterns of geodetic coupling at the CSZ. This new suite of rupture models demonstrates that the contradiction can be resolved if slip is allowed deeper into the megathrust while tapering with depth. If updip slip is larger than down-dip slip it is possible for the rupture to penetrate deeper than the more heavily weighted offshore NSHM limits (such as the $1 \mathrm{~cm}$ one) while simultaneously producing coastal subsidence, in particular as observed at paleoseismic sites.

\section{Data and Methods}

To explore whether, and to what extent, onshore slip is consistent with subsidence estimates from paleoseismic data we first generate thousands of kinematic ruptures scenarios. These simulations are preconditioned by five different models of spatially variable mean slip across the margin, described in section 2.1. We then compute the static deformation that would result from each of these models and explore which slip patterns and rupture scenarios are consistent with subsidence measurements along the coast, described in section 2.2. Finally, we estimate ground-motions for each rupture scenario to explore the shaking hazards for the subset of models that are consistent with coastal subsidence.

\subsection{Ruptures models and coseismic deformation}

When generating scenario ruptures for potential $\sim$ M9 earthquakes, it is common to use a stochastic approach (e.g. Frankel et al., 2018). The exact details of the slip distribution for the next event are unknown, but it is assumed that the slip on the fault can be treated as a spatially random field (Mai \& Beroza, 2002) with statistical properties that can be reasonably assumed. Most commonly, a VonKarman correlation function with fault dimension-dependent correlation lengths is used. From this, large suites of models can be produced either in the wavenumber (Goulet et al., 2015) or in the spatial domain (LeVeque et al., 2016). The resulting models lack some of the physical details of fully dynamic simulations, but, because they can be obtained in large numbers, allow for a more efficient exploration of parameter space.

We produce ruptures in the M8.9-M9.2 range using the approach described in Small \& Melgar (2021). Slip is allowed on the 3D slab geometry from Hayes et al. (2018), and we fix the fault length to the entire slab (Figure 1). For the VonKarman correlation function we use the correlation lengths and Hurst exponent from Melgar \& Hayes (2019). We employ the modification to the stochastic slip approach introduced by Small \& Melgar (2021). We define five different background mean models to generate five distinct families of ruptures. The first family assumes the background mean is homogenous slip and that rupture cannot propagate deeper than the most highly weighted NSHM down-dip limit, labeled the " $1 \mathrm{~cm}$ " family of ruptures. The second family, labeled "TopSSE" assumes homogenous background slip but allows it to extend deeper, to the top of the SSE zone, consistent with the deep down-dip limit used in the NSHM (Figure 1). In these models, slip is equally likely anywhere along-strike or along-dip on the fault. For the next three families we 
use as a background mean a re-scaled version of the geodetic coupling distributions from the Gamma, Gauss and Li models (Schmalzle et al.,2014, Li et al., 2018). In doing so slip is allowed anywhere where coupling is non-zero, including well below the $1 \mathrm{~cm}$. All geodetic models used here have modest amounts of slip deficit somewhere in the SSE zone, so these ruptures also allow some modest slip below the TopSSE limit and into the SSE zone. This approach does not force slip to correlate perfectly with the coupling distribution, rather, for a particular stochastic realization slip is more likely in regions of high coupling and less likely in regions of low coupling. This process yields 5,000 ruptures, examples of each family can be seen in Figure 2. For each of the rupture models, we then calculate the vertical coseismic deformation at 1 $\mathrm{km}$ intervals along the coast (Figures 2,3).

\section{$\underline{2.2 \text { Geologic estimates of coastal subsidence }}$}

The 1700 earthquake resulted in widespread subsidence of coastal marshes; quantitative estimates of this subsidence have been made by analyzing microfossils. Following sudden uplift or subsidence of an intertidal marsh, the types of foraminiferal assemblages in the water column changes. Analysis of these shifts in the abundances can be used to infer the relative sea level rise and thus the relative vertical coseismic deformation. The Bayesian transfer function (BTF) approach introduces a better way to quantify uncertainties and errors in this inference. It has been used in the CSZ by Wang et al. (2013) and Kemp et al. (2018); more details of the method can be found in Hawkes et al. (2011)

Kemp et al. (2018) updated and reanalyzed the database of Wang et al. (2013) so we use this later dataset here. However, it does not contain estimates below $43 \mathrm{~N}$ so we supplement it with a recent subsidence estimate for Humboldt Bay in northern California obtained by Padgett et al. (2021) using the BTF approach as well. The combination dataset is in Figures 2 and 3 , subsidence values of $\sim 1 \mathrm{~m}$ are common across the margin with one-sigma errors of $\sim 0.5 \mathrm{~m}$.

\subsection{Modeling ground motions}

We calculate expected ground motions for each of the 5,000 ruptures using the GMM approach. We employ the updated BC Hydro GMM (Abrahamson et al., 2018), which was designed for use in the CSZ using observed and synthetic ground-motion recordings from worldwide subduction zones (Abrahamson et al., 2016). The model was partly constrained with known slip inversions from great worldwide earthquakes. Because these are noisy, it is common to "prune" them to avoid artifacts in the resulting slip maps which contaminate estimates of source to site distance. The NGA-Sub project (Kishida et al., 2018; Bozorgnia et al., 2020) disregards slip smaller than $15 \%$ of the peak slip in each inversion. Although our models do not have noise, the minimum resolvable slip for an M8-9 earthquake used in developing the GMMs is larger than that present in our synthetics. To respect this, and accurately use the GMM, we apply the same pruning to our ruptures, assuming any "real" slip lower than the $15 \%$ pruning limit would, in the GMM slip models, be considered artifacts. We then calculate the closest distance to rupture $\left(R_{\text {rup }}\right)$, from all points in a grid of the CSZ (the "sites") to each pruned earthquake model. For each site we also obtain estimates of the Vs30 site condition from the USGS hill-slope proxy map (Allen \& Wald, 2009). From the GMM, we extract median expected ground motion quantified by peak ground acceleration and velocity (PGA, PGV) and spectral accelerations (SA). We also obtain one-sigma uncertainties for each site. In a final step we use the PGA map as input into the ground motion to intensity conversion equation (GMICE) from Worden et al. (2012). This GMICE is commonly used in worldwide applications of the U.S. Geological Survey's ShakeMap product, and produces modified Mercalli Intensity (MMI) values from other peak ground-motion intensity measures. We thus generate intensity maps for each rupture, and, for each family of ruptures, we then generate a single median intensity map. We also produce site-specific estimates of the intensities at important cities across the margin.

\section{Results}

Figure 2 shows an example rupture for each of the five families of models. Summary statistics for all 5000 ruptures are in Supplementary Figure S1 (models are available for download, see the Data Availability 
Statement). For the Gauss, Gamma, and Li ruptures the slip distributions are correlated with the underlying coupling distributions; large coseismic slip generally occurs in regions with large slip rate deficits. Meanwhile, in the $1 \mathrm{~cm}$ and TopSSE ruptures slip does not correlate with any coupling model. An important feature of the rupture models derived from estimates of slip rate deficit is that the slip tapers with depth, like in the coupling distributions. The five examples in Figure 2 were selected because all but the TopSSE one have good RMS fits to the coastal subsidence data; their vertical coseismic deformation signal fits the geologic estimates to within RMS $<0.5 \mathrm{~m}$, which is comparable to the one-sigma uncertainties in the estimates themselves.

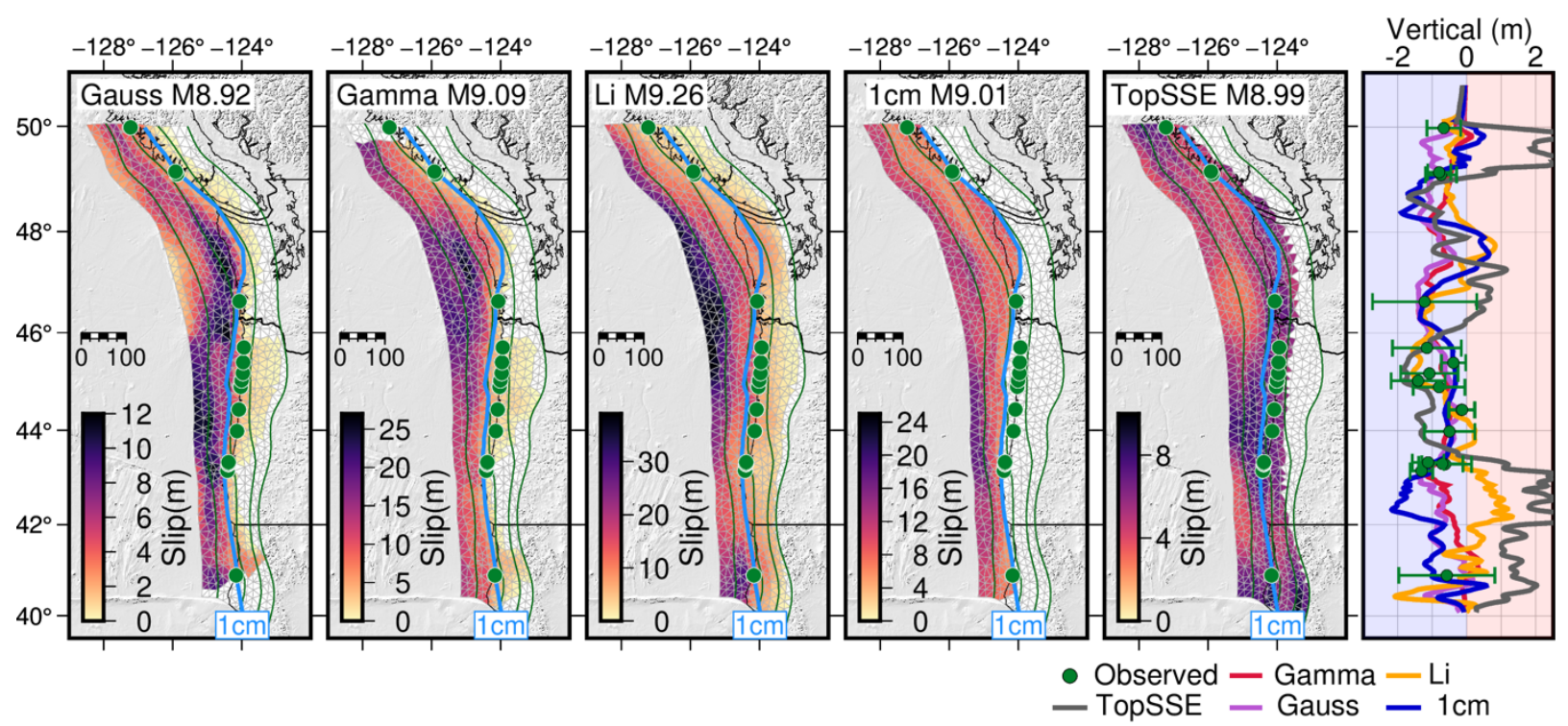

Figure 2. Example ruptures for each of the four families. Gamma and Gauss models use the geodetic coupling distributions from Schmalzle et al. (2014). Li models use the model from Li et al. (2018). The $1 \mathrm{~cm}$ and TopSSE models use a homogenous background mean model but do not allow slip below the highest weighted down-dip limit preferred by the National Seismic Hazard Map (Petersen et al., 2020) and below the top of the SSE zone. Green circles show the coastal subsidence estimates with $95 \%$ confidence intervals from microfossil analyses from Kemp et al. (2018) and Padgett et al. (2021). Shown as well is the modeled subsidence for each of the demonstration ruptures. Blue line is the highest weighted down-dip limit from the National Seismic Hazard Map.

The vertical coseismic deformation at the coast for all models is summarized in Figure 3. Consistent with Wirth \& Frankel (2019), the TopSSE ruptures, which allow slip below the $1 \mathrm{~cm}$ limit, without tapering with depth, do not fit the geologic subsidence (median RMS $=1.3 \mathrm{~m}$ ). We do not consider them further when exploring the implications of deep slip. Meanwhile, the models calculated using the shallower $1 \mathrm{~cm}$ downdip limit fit the subsidence well with a median RMS misfit to the geologic estimates of $0.6 \mathrm{~m}$. However, so do the Gamma and Gauss models, with median RMS of $0.53 \mathrm{~m}$ and $0.46 \mathrm{~m}$ respectively. The ruptures produced using the Li coupling model yield a slightly poorer median RMS fit of $0.7 \mathrm{~m}$ and are biased towards underestimating the subsidence. However, even though the median RMS misfit values differ, for four of the five families of models, there are several scenarios (Figure 2) that fit the subsidence estimates below RMS $=0.5 \mathrm{~m}$.

In British Columbia, Washington and Oregon, the four families of models that fit the geologic data well and have overall similar subsidence patterns. However, in northern Washington, specifically around the Olympic peninsula where there are no known estimates of coastal subsidence or uplift, the models differ. Ruptures generated using the $1 \mathrm{~cm}$ down-dip limit systematically predict uplift of the coast there. Meanwhile, the geodetically-derived ruptures favor mild subsidence. Another area with significant differences is Northern 
California. All models predict subsidence at the OR/CA border but predict mostly uplift farther south. This transition occurs faster in the geodetically-derived models, and as a result, does not fit the geologic estimate from Padgett et al. (2021) for Humboldt Bay. At this site, the $1 \mathrm{~cm}$ models fit the geologic estimates much better.

These assumptions produce different impacts on ground-motions. In Figure 4 and Supplementary Figure S2 are maps with the median expected intensities across the region, as well as specific values at significant population centers. Median intensities range from about MMI 5.5 to as high as MMI 7 for each city. Uncertainties are about +/- MMI 0.8 for most estimates. South of the OR/WA border, the geodetic-based families produce systematically higher intensities than the WF19 models. These differences are as high as 1.2 MMI units in southern Oregon. For the northern CSZ, somewhat surprisingly the Gauss models produce lower intensities with as much as $0.5 \mathrm{MMI}$ unit difference on Vancouver islands. The Gamma model has smaller (MMI+/-0.2) differences with the $1 \mathrm{~cm}$ model north of Seattle. The Li models, which allow for the deepest slip (Figures 1,2), have systematically higher ground motions than $1 \mathrm{~cm}$ everywhere except for the northern third of Vancouver Island.

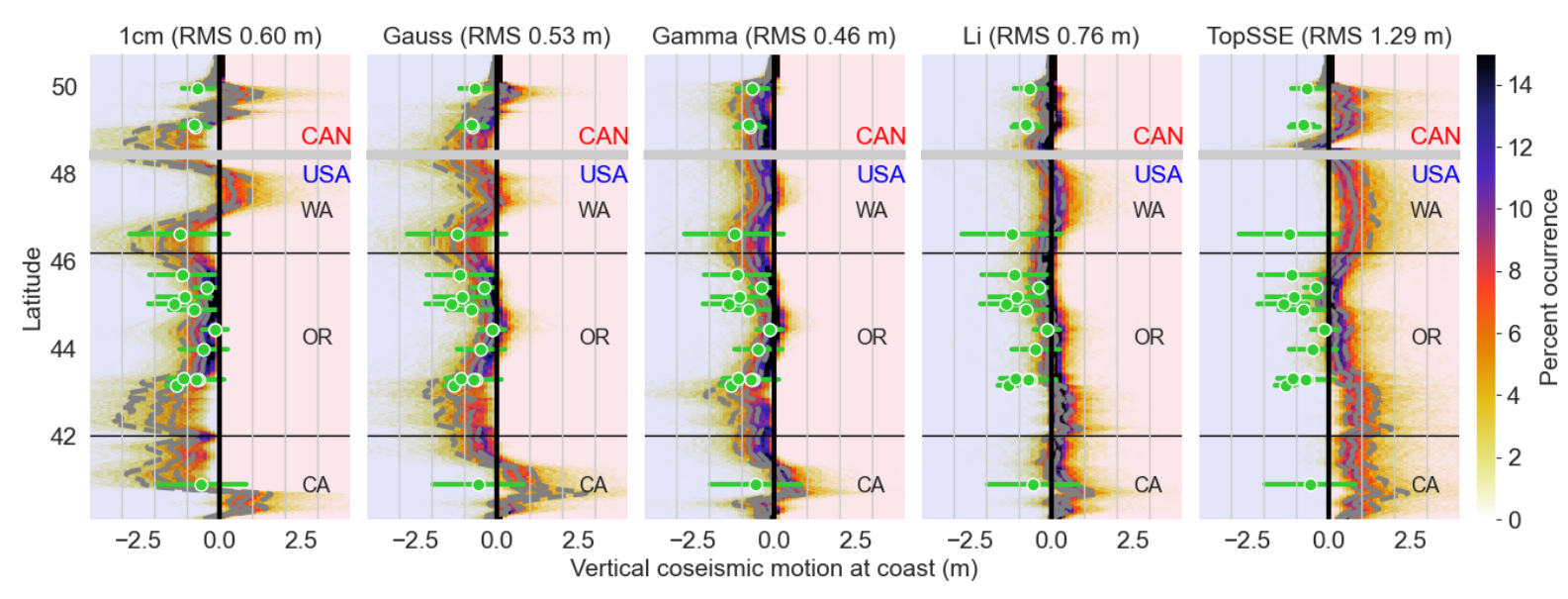

Figure 3. Empirical distribution of coastal deformation from all rupture models compared to geologic estimates from Kemp et al. (2018) and Padgett et al. (2021). Positive coseismic motion represents uplift, negative represents subsidence. For each latitude slice the colors indicate how frequently the rupture models attain a certain value of deformation. The grey lines are the median and $25^{\text {th }}$ and $75^{\text {th }}$ percentile values of deformation. The green symbols are the geologic subsidence estimates with $95 \%$ confidence intervals. RMS misfits from the median subsidence is indicated in the titles.

\section{Discussion}

\subsection{The down-dip limit of coseismic slip}

The TopSSE family of ruptures show that indeed, deep slip with no depth constraints does not fit the geologic subsidence data well. There is no rupture in that family with RMS $<0.8 \mathrm{~m}$, and most have RMS in excess of $1.5 \mathrm{~m}$. But, by using several published coupling distributions as background means when generating the ruptures, deep megathrust slip, past the $1 \mathrm{~cm}$ limit, and even into the SSE zone can be made consistent with coastal subsidence.

An important issue is whether, beyond having good RMS fits, the different families of models can produce widespread subsidence as is inferred to have occurred during the 1700 earthquake. Figure 5 shows the empirical probability density functions (PDFs) calculated using a kernel density estimate for the coseismic deformation at each paleoseismic point and for each family of ruptures. The Gamma models easily produce this, struggling only with one of the northern California points. The Gauss ruptures show similar behavior, albeit also struggling with the northernmost point in BC. The Li models frequently lead to coastal subsidence at any one given point but tend to more frequently produce uplift as well. All geodetically informed rupture 
families are capable of wholesale subsidence, Figure S3 shows that the Gamma models produce simultaneous subsidence at all sites $\sim 25 \%$ of the time, while the Gauss and Li ruptures do so $5-10 \%$ of the time. Meanwhile the $1 \mathrm{~cm}$ ruptures perform at the same level as the Gamma ruptures producing subsidence at all coastal points $\sim 25 \%$ of the time. This shows that yes, the $1 \mathrm{~cm}$ down-dip limit is conducive to marginwide subsidence but this is at the expense of the geophysical contradiction of a large swath of the megathrust having simultaneously non-zero coupling and no coseismic participation.

Models with deep slip overcome this contradiction. If slip tapers with depth (e.g. Figures 2,3), the subsidence generated by larger amplitude, shallow offshore slip is enough to overcome any uplift generated by more muted and deeper slip. Such rupture models avoid having a region between the $1 \mathrm{~cm}$ limit and the SSE zone where geodesy images coupling, but where previous research has suggested coseismic rupture is unlikely because it does not fit the margin-scale paleoseismic subsidence (Wirth \& Frankel, 2019). For this zone, assuming the slip-deficit rates have remained constant at $\sim 10 \mathrm{~mm} / \mathrm{yr}$ since the 1700 earthquake leads to at least $\sim 3.2 \mathrm{~m}$ of accumulated slip. The slip models we have generated are roughly consistent with this amount. Thus, slip that tapers with depth and extends at least to the top of the SSE zone, such as in most of the gamma models, and perhaps into it, as in the Li models, should be considered in hazard calculations. Currently, deep slip past the $1 \mathrm{~cm}$ limit is downweighted in the NSHM and any slip into the SSE zone is not considered possible (Petersen et al., 2020).
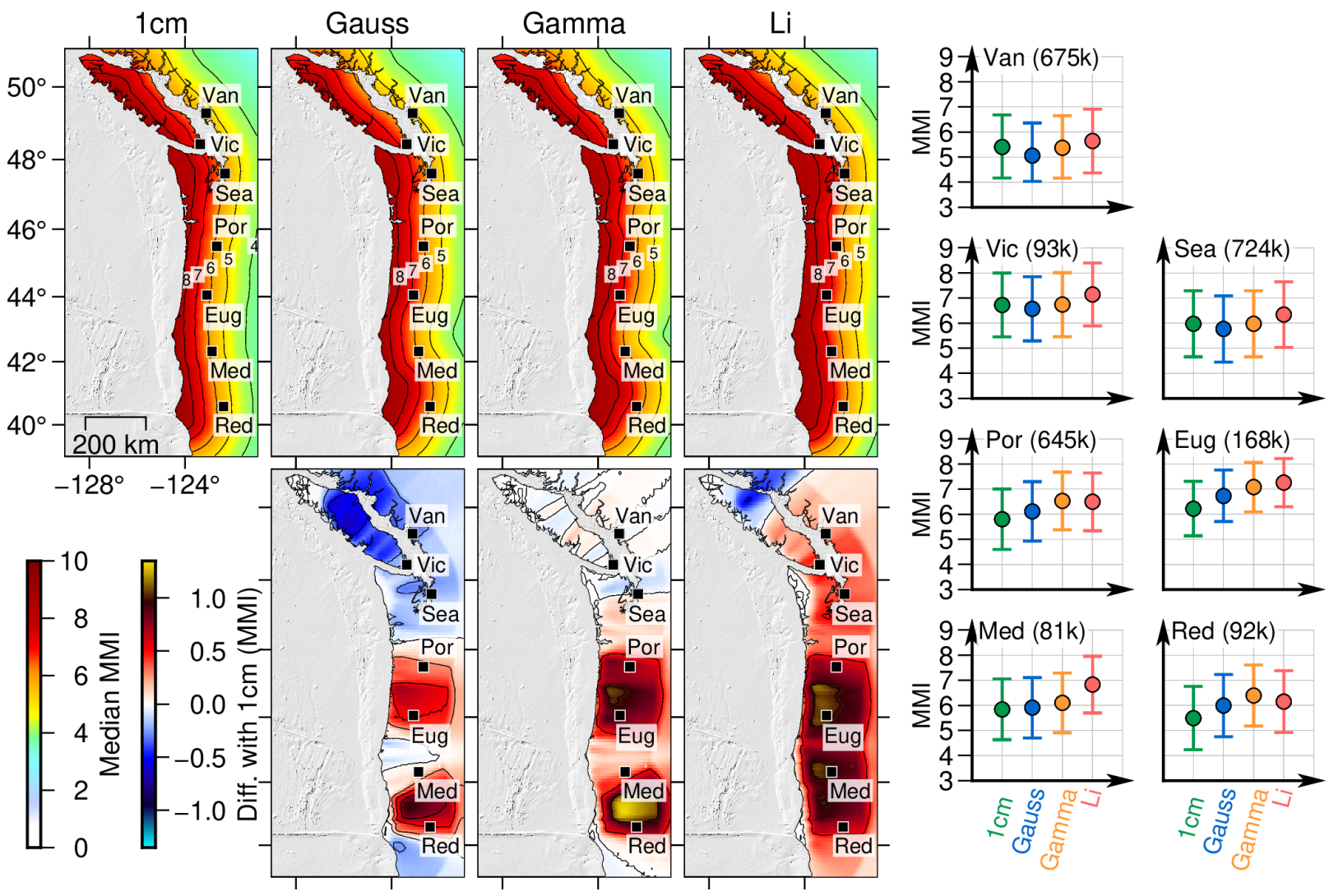

Figure 4. Median ground motion intensities for all ruptures in each family of models. The differences are shown with respect to the $1 \mathrm{~cm}$ NSHM family of ruptures. Positive values indicate the geodetic-based estimates are higher than the $1 \mathrm{~cm}$ models, negative values indicate the inverse situation. The contours are every $1 \mathrm{MMI}$ unit. Labeled population centers are Vancouver, BC (Van), Victoria, BC (Vic), Seattle, WA (Sea), Portland, OR (Por), Eugene, OR (Eug), Medford, OR (Med), and Redding, CA (Red). The expected median intensities at each of these sites and for each family of ruptures are shown in the scatter plots with one-sigma uncertainties. Population estimates for each city are shown in parentheses. 

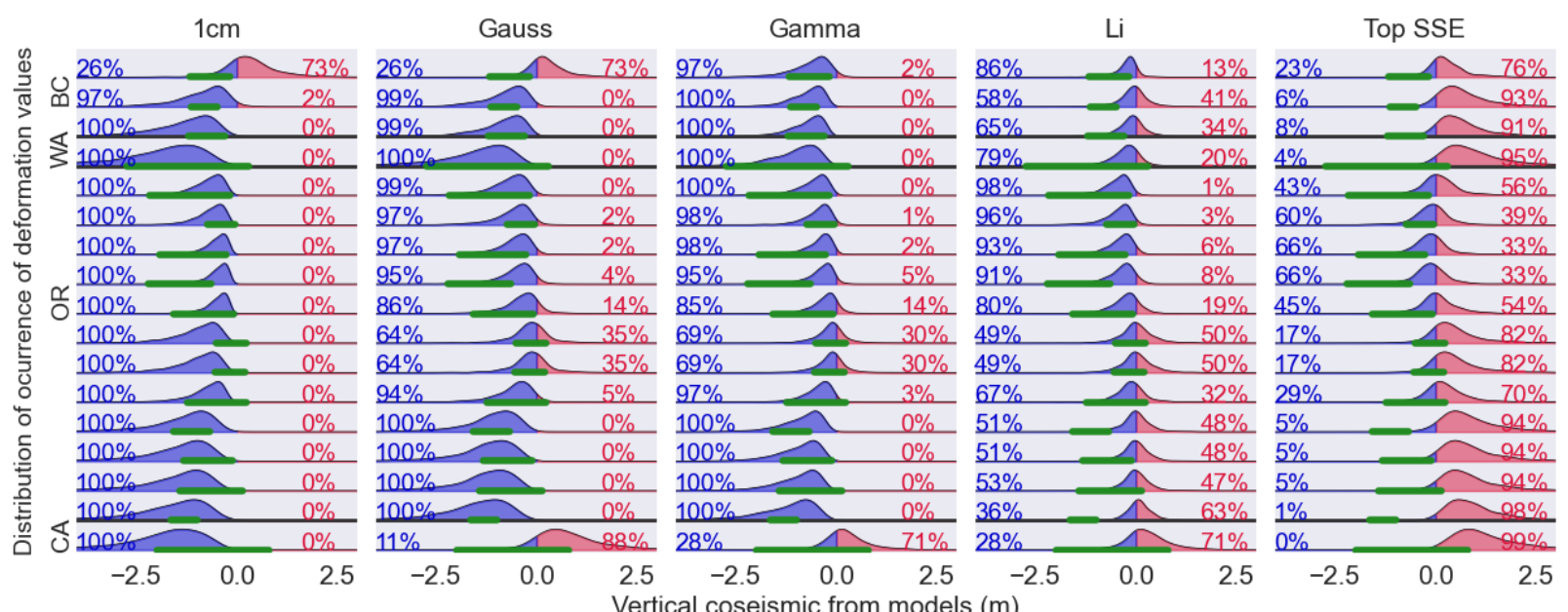

Figure 5. Empirical probability density functions (PDFs) of coseismic deformation at each paleoseismic site for each of the five families of ruptures. Blue indicates subsidence and red indicates uplift; the number next to each PDF is how frequently uplift or subsidence occurs overall. The thick green bars below each PDF are the coseismic deformation estimates with 95\% confidence at each site from Figure 3

Multiple pieces of evidence suggest that this deep rupture is possible. First, the coupling model of Li et al. (2018) suggests $\sim 5 \mathrm{~mm} / \mathrm{yr}$ of slip deficit rate within the SSE zone. Ruptures from this family produce slip into the SSE zone but generally fit the coastal subsidence estimates with higher misfits than the other models. However, there are still some ruptures (Figure 2) that can easily fit the estimates to within uncertainties. Figure S4 shows that there are 23 ruptures with RMS $<0.5 \mathrm{~m}$ which have mean slip of $\sim 1$ $2 \mathrm{~m}$ in the SSE zone. This is consistent with the $\sim 5 \mathrm{~mm} / \mathrm{yr}$ slip rate deficit suggested by the coupling. Second, dynamic rupture models of the Cascadia Subduction Zone produce significant slip within the SSE region. These simulations prescribe normal and shear stress conditions that are typically 10's of MPa on the shallow, highly coupled portions of the megathrust and taper to significantly smaller values of $<=1 \mathrm{MPa}$ in the SSE region, consistent with observations of nearly lithostatic pore fluid pressure in regions hosting SSEs (Ramos and Huang, 2019; Ramos et al., 2021). These stress conditions promote rupture penetration well into the ETS region for most of the scenarios explored and produce appreciable slip, e.g. $20 \mathrm{~m}$, there (Ramos and Huang, 2019). While this amount of slip in the ETS region is considerable and not consistent with the coastal subsidence estimates (see Top SSE models presented here), the general result that downdip slip penetration is difficult to stop supports the possibility of coseismic slip penetrating into the SSE region. Finally, coseismic rupture penetration into regions hosting slow slip events has been observed. For example, Lin et al. (2020) showed that coseismic slip in the 2018 M7.1 Hawaii earthquake overlapped significantly with an adjacent fault segment that regularly hosts slow slip events.

Here we note once again that the geologic estimates of coastal subsidence are useful guides (Figure 2,3), but they have a non-negligible level of uncertainty. It is likely they record the early post-seismic deformation and near-field motions typically include extra subsidence from viscoelastic relaxation and afterslip (e.g. Sun \& Wang, 2015) the details depend on the co-seismic and afterslip distributions (Sun \& Wang, 2015). Furthermore, measurements of coastal subsidence contain bias in their spatial distribution, and are not produced on a uniform grid along the coastline. This sampling bias is also a source of uncertainty that cannot be ignored.

\section{$\underline{4.2 \text { Implications for ground motion }}$}

We emphasize that we do not present here an authoritative ground-motion assessment for the next great earthquake. Rather, we try to show that the potential impacts of allowing rupture to penetrate deeper into the megathrust can be significant. For example, for the city of Eugene, OR, the median motion in the NSHM 
models is MMI6.2 (strong shaking) while for the Li ruptures it can be as high as MMI7.2 (very strong shaking). Accounting for the uncertainties, the ground motions could reasonably be as high as MMI8.2 (severe shaking). Differences of $1 \mathrm{MMI}$ unit can have an outsized impact in hazard assessments, and on the loads that buildings infrastructure are required to withstand.

These differences in the ground motions are most evident where the $1 \mathrm{~cm}$ limit departs significantly from the coupling models. This is particularly true offshore Oregon and California, where the differences in median ground motions are largest. This down-dip limit was first proposed for the 2014 update to the USGS hazard map (Frankel et al., 2015) and it was meant to follow the $10 \mathrm{~mm} / \mathrm{yr}$ slip deficit rate contour as known at the time. However, it is clear from (Figure 1) that, when compared to more recent coupling estimates, this limit does not follow the contour anymore.

The choice of how to prune the slip models can have a significant impact in the resulting ground motions. When computing the BC Hydro GMM, Abrahamson et al. (2016) removed slip that was less than $15 \%$ of the peak. This removes artifacts, but likely also removes some real slip and artificially reduces the size of the source. This is unavoidable when dealing with real, noisy, slip inversions. To make the comparison fair, we have pruned our slip models in the same way. But, because the ruptures from the locking models have slip tapering with depth, it is precisely this deeper slip that is most often removed by this pruning process (Supplementary Figures S5,S6). Therefore, the Gauss ruptures lead to lower ground motions than the $1 \mathrm{~cm}$ ruptures in the northern CSZ. In contrast, because the $1 \mathrm{~cm}$ ruptures do not have the downdip tapering effect, they are less affected by pruning. If we compute the ground motions on the full, un-pruned, slip distributions, the ground motions for the geodetic-based models increase significantly and are substantially higher than from the $1 \mathrm{~cm}$ models (Supplementary Figures S5,S6). The discrepancy grows from up to 1.3 $\mathrm{MMI}$ units difference to being as much as $2.3 \mathrm{MMI}$ units larger. We still maintain that the pruned ground motion estimates from (Figure 4) are more realistic and better honor the model, given how the GMMs was developed.

Lastly, it is important to note that we do not use the same complex site effects in the region as the new CSZ ground motion estimates (Wirth et al., 2021). In some regions such as the Seattle basin, known amplification effects would certainly further increase ground-motions. In other regions such as the Portland basin, sedimentary structures that are still relatively unconstrained would result in higher ground motions as well.

\section{$\underline{4.3 \text { Limitations and necessary improvements }}$}

One limitation of our ground-motion estimation approach is that we only use $R_{\text {rup }}$, the minimum distance from a particular site to the rupture, without considering whether that site is close to a high-slip patch and thus more prone to elevated ground motions. Thompson \& Baltay (2018) have shown that mean rupture distance, a quantity weighted by the proximity to patches with different amounts of slip, produces more physically meaningful results, but there are no subduction zone GMMs that currently use this metric. This could potentially lessen the ground motions from deeper slip given that, while the slip comes further onshore and closer to many locations, it does so with reduced slip from the tapering effect introduced by the coupling models.

We also do not consider the effects of high stress-drop patches or strong-motion generating areas (SMGAs). For large megathrust events it has been noted that, to model the gross features of high-frequency shaking, SMGAs are necessary (e.g. Nozu \& Irikura, 2008). Where these occur in the megathrust is a matter of some debate. For the M9.0 Tohoku-oki earthquake, Suzuki et al. (2011) noted that most of the strong motion pulses originated in deep SMGAs close to the down-dip limit. Wirth \& Frankel (2019) considered SMGAs for hypothetic CSZ ruptures, and also placed them mostly down-dip. It stands to reason that if slip can penetrate below the $1 \mathrm{~cm}$ limit, then the SMGAs in the CSZ could potentially be closer to population centers than previously thought, increasing shaking and seismic hazard (Wirth \& Sahakian et al., 2022). However, a systematic analysis of where SMGAs occur has not been possible on worldwide events, let alone for the CSZ, so this is speculative. 
There is a large discrepancy between the $1 \mathrm{~cm}$ models and the ruptures based on geodetic coupling at the southern terminus of the CSZ. The geodetic-based models do not match the geologic estimate of coastal subsidence well. However, we note that within the $95 \%$ confidence the Padgett et al. (2021) estimate does allow for some modest uplift to have occurred. Similarly, Carver et al. (1994) noted up to $\sim 1 \mathrm{~m}$ of uplift during the 1992 M7.2 Mendocino earthquake. The Schmalzle et al. (2014) and Li et al. (2018) coupling models are obtained from inversion of regional GNSS velocities. These are difficult to fit at the triple junction where the San Andreas fault and numerous crustal faults make the inter-seismic deformation modeling challenging. It is possible that the coupling models at the CSZs southern terminus need more detailed work.

\section{Conclusions}

The typically assumed shallow down-dip rupture limit for the CSZ is motivated by widespread observations of coastal subsidence across the margin. This limit is inconsistent with geodetic coupling models which show non-negligible slip deficit rates deeper in the megathrust. Here we have shown that ruptures can penetrate as deep as the SSE zone (and into it) and still produce coastal subsidence if the slip distribution tapers with depth. The subsidence produced by large shallow slip is enough to overcome any uplift from more muted deeper slip. We have shown that models that have these features can be consistent, within uncertainties, with the geologic estimates of coastal subsidence. The implications of a deeper down-dip limit are significant for ground motion. Deeper ruptures will be closer to major population centers and can lead to overall larger intensity shaking.

\section{Data Availability Statement}

The kinematic ruptures were generated using the FakeQuakes code which is part of the MudPy source modeling toolkit available on GitHub (https://github.com/dmelgarm/MudPy), the latest version is archived ione Zenodo at Melgar (2021). The rupture models and their coastal subsidence estimates are archived on Zenodo at (Melgar et al., 2021). The ground motions were calculated using the OpenQuake Engine framework (Pagani et al., 2014, https://github.com/gem/oq-engine).

\section{Acknowledgments}

We'd like to thank the associate editor Lucy Flesch, and reviewers Rich Briggs and Art Frankel for a critical reading of the manuscript. We also thank Brian Atwater, Art Frankel, and Erin Wirth for fruitful discussions. We are indebted to Noel Bartlow for sharing her SSE estimates, Jason Padgett and Andy Kemp for the coastal subsidence estimates and discussions on their intricacies. We also thank Gina Schmalzle, Shaoyang $\mathrm{Li}$, and Kelin Wang for sharing and discussing their coupling models. This work was partially funded by NASA grants \# 80NSSC19K0360, 80NSSC19K1104, and 80NSSC21K0841.

\section{References}

Abrahamson, N., Gregor, N., \& Addo, K. (2016). BC Hydro ground motion prediction equations for subduction earthquakes. Earthquake Spectra, 32(1), 23-44.

Abrahamson, N. A., Keuhn, N., Gulerce, Z., Gregor, N., Bozognia, Y., Parker, G., Stewart, J., Chiou, B., Idriss, I. M., Campbell, K. and Youngs, R. (2018) "Update of the BC Hydro Subduction Ground-Motion Model using the NGA-Subduction Dataset", Pacific Earthquake Engineering Research Center (PEER) Technical Report, PEER 2018/02.

Allen, T. I., \& Wald, D. J. (2009). On the use of high-resolution topographic data as a proxy for seismic site conditions (VS 30). Bulletin of the Seismological Society of America, 99(2A), 935-943.

Atwater, B. F., Musumi-Rokkaku, S., Satake, K., Tsuji, Y., Ueda, K., \& Yamaguchi, D. K. (2005). The orphan tsunami of 1700: Japanese clues to a parent earthquake in North America. University of Washington Press.

Bartlow, N. M. (2020). A long-term view of episodic tremor and slip in Cascadia. Geophysical Research Letters, 47(3), e2019GL085303. 
Bozorgnia, Y., \& Stewart, J. P. (2020). Data Resources for NGA-Subduction Project, PEER Report 2020/02. Berkeley, CA: Pacific Earthquake Engineering Research Center.

Braunmiller, J., \& Nábělek, J. (2002). Seismotectonics of the Explorer region. Journal of Geophysical Research: Solid Earth, 107(B10), ETG-1.

Burgette, R. J., Weldon, R. J., \& Schmidt, D. A. (2009). Interseismic uplift rates for western Oregon and along-strike variation in locking on the Cascadia subduction zone. Journal of Geophysical Research: Solid Earth, 114(B1).

Carver, G. A., Jayko, A. S., Valentine, D. W., \& Li, W. H. (1994). Coastal uplift associated with the 1992 Cape Mendocino earthquake, northern California. Geology, 22(3), 195-198.

DeMets, C., Gordon, R. G., \& Argus, D. F. (2010). Geologically current plate motions. Geophysical Journal International, 181(1), 1-80.

Frankel, A., Wirth, E., Marafi, N., Vidale, J., \& Stephenson, W. (2018). Broadband synthetic seismograms for magnitude 9 earthquakes on the Cascadia megathrust based on 3D simulations and stochastic synthetics, Part 1: Methodology and overall results. Bulletin of the Seismological Society of America, 108(5A), 2347-2369.

Goldfinger, C., Nelson, C. H., Morey, A. E., Johnson, J. E., Patton, J. R., Karabanov, E. B. \& Enkin, R. J. (2012) Turbidite event history-Methods and implications for Holocene paleoseismicity of the Cascadia subduction zone (No. 1661-F). US Geological Survey.

Goldfinger, C., Galer, S., Beeson, J., Hamilton, T., Black, B., Romsos, C., ... \& Morey, A. (2017). The importance of site selection, sediment supply, and hydrodynamics: A case study of submarine paleoseismology on the northern Cascadia margin, Washington USA. Marine Geology, 384, 4-46.

Goulet, C. A., Abrahamson, N. A., Somerville, P. G., \& Wooddell, K. E. (2015). The SCEC broadband platform validation exercise: Methodology for code validation in the context of seismic-hazard analyses. Seismological Research Letters, 86(1), 17-26.

Hawkes, A. D., B. P. Horton, A. R. Nelson, C. H. Vane, and Y. Sawai (2011), Coastal subsidence in Oregon, USA, during the giant Cascadia earthquake of AD 1700, Quat. Sci. Rev., 30, 364- 376, doi:10.1016/j.quascirev.2010.11.017.

Hayes, G. P., Moore, G. L., Portner, D. E., Hearne, M., Flamme, H., Furtney, M., \& Smoczyk, G. M. (2018). Slab2, a comprehensive subduction zone geometry model. Science, 362(6410), 58-61.

Hyndman, R. D., \& Wang, K. (1995). The rupture zone of Cascadia great earthquakes from current deformation and the thermal regime. Journal of Geophysical Research: Solid Earth, 100(B11), 2213322154.

Kemp, A. C., Cahill, N., Engelhart, S. E., Hawkes, A. D., \& Wang, K., (2018) Revising Estimates of Spatially Variable Subsidence during the AD 1700 Cascadia Earthquake Using a Bayesian Foraminiferal Transfer Function. Bulletin of the Seismological Society of America, 108(2), 654-673.

Kishida, T., Contreras, V., Bozorgnia, Y., Abrahamson, N. A., Ahdi, S. K., Ancheta, T. D., ... \& Youngs, R. R. (2018). NGA-Sub ground motion database.

LeVeque, R. J., Waagan, K., González, F. I., Rim, D., \& Lin, G. (2016) Generating random earthquake events for probabilistic tsunami hazard assessment. In Global Tsunami Science: Past and Future, Volume I (pp. 3671-3692). Birkhäuser, Cham.

Li, S., Wang, K., Wang, Y., Jiang, Y., \& Dosso, S. E. (2018) Geodetically inferred locking state of the Cascadia megathrust based on a viscoelastic Earth model. Journal of Geophysical Research: Solid Earth, 123(9), 8056-8072.

Lin, J. T., Aslam, K. S., Thomas, A. M., \& Melgar, D. (2020). Overlapping regions of coseismic and transient slow slip on the Hawaiian décollement. Earth and Planetary Science Letters, 544, 116353.

Lin, J.-T., D. Melgar, A. M. Thomas, and J. Searcy (2021) Early warning for great earthquakes from characterization of crustal deformation patterns with deep learning. JGR-Solid Earth.

Mai, P. M., \& Beroza, G. C., A spatial random field model to characterize complexity in earthquake slip. Journal of Geophysical Research: Solid Earth, 107(B11), ESE-10. (2002).

Melgar, D., \& Hayes, G. P. (2019). The correlation lengths and hypocentral positions of great earthquakes. Bulletin of the Seismological Society of America, 109(6), 2582-2593. 
Melgar, D., Sahakian, V.J., \& Thomas, A.M. (2021). Full margin Cascadia earthquake models [Data set]. Zenodo. doi:10.5281/zenodo.5397279

Melgar, D. (2021). dmelgarm/MudPy: v1.3. Zenodo. doi:10.5281/zenodo.5397091

Nelson, A.R., DuRoss, C.B., Witter, R.C., Kelsey, H.M., Engelhart, S.E., Mahan, S.A., Gray, H.J., Hawkes, A.D., Horton, B.P., and Padgett, J.S., 2021, A maximum rupture model for the central and southern Cascadia subduction zone-reassessing ages for coastal evidence of megathrust earthquakes and tsunamis: Quaternary Science Reviews, v. 261, p. 106922, doi:10.1016/j.quascirev.2021.106922.

Newton, T. J., Weldon, R., Miller, I. M., Schmidt, D., Mauger, G., Morgan, H., \& Grossman, E. (2021). An Assessment of Vertical Land Movement to Support Coastal Hazards Planning in Washington State. Water, 13(3), 281.

Nozu, A., \& Irikura, K. (2008). Strong-motion generation areas of a great subduction-zone earthquake: waveform inversion with empirical Green's functions for the 2003 Tokachi-oki earthquake. Bulletin of the Seismological Society of America, 98(1), 180-197.

Okada, Y. (1985). Surface deformation due to shear and tensile faults in a half-space. Bulletin of the seismological society of America, 75(4), 1135-1154.

Padgett, J.S., Engelhart, S.E., Kelsey, H.M., Witter, R.C., Cahill, N., and Hemphill-Haley, E., 2021, Timing and amount of southern Cascadia earthquake subsidence over the past 1700 years at northern Humboldt Bay, California, USA: GSA Bulletin, doi:10.1130/B35701.1.

Pagani, M., Monelli, D., Weatherill, G., Danciu, L., Crowley, H., Silva, V., ... \& Vigano, D. (2014). OpenQuake engine: An open hazard (and risk) software for the global earthquake model. Seismological Research Letters, 85(3), 692-702.

Petersen, M. D., et al. (2020). The 2018 update of the US National Seismic Hazard Model: Overview of model and implications. Earthquake Spectra, 36(1), 5-41.

Satake, K., Wang, K., \& Atwater, B. F. (2003). Fault slip and seismic moment of the 1700 Cascadia earthquake inferred from Japanese tsunami descriptions. Journal of Geophysical Research: Solid Earth, 108(B11).

Savard, G., Bostock, M. G., Hutchinson, J., Kao, H., Christensen, N. I., \& Peacock, S. M. (2020). The northern terminus of Cascadia subduction. Journal of Geophysical Research: Solid Earth, 125(6), e2019JB018453.

Schmalzle, G. M., McCaffrey, R., \& Creager, K. C. (2014) Central Cascadia subduction zone creep. Geochemistry, Geophysics, Geosystems, 15(4), 1515-1532, (2014).

Small, D. T., \& Melgar, D. (2021). Geodetic Coupling Models as Constraints on Stochastic Earthquake Ruptures: An Example Application to PTHA in Cascadia. Journal of Geophysical Research: Solid Earth, 126(7), e2020JB021149.

Sun, T., \& Wang, K. (2015). Viscoelastic relaxation following subduction earthquakes and its effects on afterslip determination. Journal of Geophysical Research: Solid Earth, 120(2), 1329-1344.

Suzuki, W., Aoi, S., Sekiguchi, H., \& Kunugi, T. (2011). Rupture process of the 2011 Tohoku-Oki megathrust earthquake (M9. 0) inverted from strong-motion data. Geophysical Research Letters, 38(7).

Thompson, E. M., \& Baltay, A. S. (2018). The case for mean rupture distance in ground-motion estimation. Bulletin of the Seismological Society of America, 108(5A), 2462-2477.

Walton, M., Staisch, L., et al. (2021). Toward an Integrative Geological and Geophysical View of Cascadia Subduction Zone Earthquakes. Annual Review of Earth and Planetary Sciences, 49, 367-398.

Wang, P. L., Engelhart, S. E., Wang, K., Hawkes, A. D., Horton, B. P., Nelson, A. R., \& Witter, R. C. (2013). Heterogeneous rupture in the great Cascadia earthquake of 1700 inferred from coastal subsidence estimates. Journal of Geophysical Research: Solid Earth, 118(5), 2460-2473.

Witter, R. C., Briggs, R. W., Engelhart, S. E., Gelfenbaum, G., Koehler, R. D., \& Barnhart, W. D. (2014). Little late Holocene strain accumulation and release on the Aleutian megathrust below the Shumagin Islands, Alaska. Geophysical Research Letters, 41(7), 2359-2367.

Wirth, E. A., Frankel, A. D., Marafi, N., Vidale, J. E., \& Stephenson, W. J. (2018). Broadband synthetic seismograms for magnitude 9 earthquakes on the Cascadia megathrust based on 3D simulations and stochastic synthetics, Part 2: Rupture parameters and variability. Bulletin of the Seismological Society of America, 108(5A), 2370-2388. 
Wirth, E. A., \& Frankel, A. D. (2019). Impact of Down-Dip Rupture Limit and High-Stress Drop Subevents on Coseismic Land-Level Change during Cascadia Megathrust Earthquakes. Bulletin of the Seismological Society of America, 109(6), 2187-2197.

Wirth, E. A., Grant, A., Marafi, N. A., \& Frankel, A. D. (2021). Ensemble ShakeMaps for magnitude 9 earthquakes on the Cascadia subduction zone. Seismological Society of America, 92(1), 199-211.

Wirth, E.A., Sahakian, V.J., Wallace, L.M., Melnick, D. (2022). The occurrence and hazards of great subduction zone earthquakes. Nature Reviews Earth and Environment, in press.

Worden, C. B., Gerstenberger, M. C., Rhoades, D. A., \& Wald, D. J. (2012). Probabilistic relationships between ground-motion parameters and modified Mercalli intensity in California. Bulletin of the Seismological Society of America, 102(1), 204-221. 